\title{
Efeito dos níveis de triptofano digestível em dietas para codornas japonesas em postura
}

\author{
Sandra Regina Freitas Pinheiro ${ }^{1^{*}}$, Sergio Luiz de Toledo Barreto ${ }^{2}$, Luiz Fernando Teixeira \\ Albino $^{2}$, Horacio Santiago Rostagno ${ }^{2}$, Regina Tie Umigi ${ }^{1}$, Claudson Oliveira Brito ${ }^{3}$
}

\footnotetext{
1 Programa Pós-graduação em Zootecnia, UFV, Viçosa - MG;

2 Departamento de Zootecnia, DZO, UFV, Viçosa - MG.

3 Poli-Nutri Alimentos Ltda.
}

RESUMO - O nível dietético adequado (0,12;0,16;0,20;0,24 e 0,28\%) de triptofano digestível foi avaliado em 400 codornas japonesas de 21 a 30 semanas de idade, fase de postura. As codornas foram alojadas em gaiolas de $125 \mathrm{~cm}^{2} / \mathrm{ave}$, com peso inicial de 158,50 g e produção média de ovos de 84,50\%. O delineamento experimental foi em blocos casualizados, constituído por oito blocos, cinco tratamentos, oito repetições de dez aves/repetição e três períodos experimentais de 21 dias cada. Foram avaliados os parâmetros de desempenho das aves, consumo de ração (g/ave/dia), consumo de triptofano (mg/ave/dia), produção de ovos (\%/ave/dia), peso médio dos ovos (g), massa de ovos (kg/ave/dia) e conversão alimentar (kg de ração/kg de ovos e por dúzia de ovos). Somente as variáveis consumo de triptofano e produção de ovos apresentaram efeitos significativos dos níveis de triptofano nas dietas. As respostas de desempenho das codornas, respeitando o ajuste estatístico obtido por meio de modelos de regressão linear e do modelo descontínuo LRP, e a interpretação biológica permitem concluir que, para se obter o melhor desempenho produtivo, as dietas de codornas devem conter o nível de 0,21\% de triptofano digestível, o que resulta no consumo diário de 45,0 mg/ave de triptofano, correspondendo à relação triptofano: lisina digestível de $21 \%$.

Palavras-chave: aminoácido, Coturnix coturnix japonica, exigência, serotonina

\section{Dietary digestible tryptophan levels for Japanese laying quails}

\begin{abstract}
The adequate level $(0.12,0.16,0.20,0.24$, and $0.28 \%)$ of the dietary digestible tryptophan was evaluated in 400 laying Japanese quail from 21 to 30 weeks old. The animals were housed in laying cages, with initial weight of $158.50 \mathrm{~g}$ and egg production average of $84.50 \%$. A completely randomized blocks design, with eight blocks, five diets, eight replicates of ten birds per replicate and three experimental periods of 21 days each was used. Feed intake (g/bird/day), digestible tryptophan intake (mg/bird/day), egg production (\%/bird/day), egg weight (g), egg mass (kg/bird/day) and feed conversion (kg feed intake per kg eggs and dozen eggs) were the characteristics evaluated. Only the characteristics digestible tryptophan intake and egg production rate show significant effects of digestible tryptophan levels in the diets. Performance response of the Japanese quails in posture, regarding the adjustment obtained through models of linear regression and broken-line regression model, and the biological interpretation, allow to conclude that to obtain the best productive performance, the Japanese quails diets should contain the level of $0.21 \%$ digestible tryptophan, that results in a daily intake of $45.0 \mathrm{mg} / \mathrm{bird}$ of digestible tryptophan, corresponding to the digestible tryptophan: digestible lysine ratio of $21 \%$.
\end{abstract}

Key Words: amino acids, Coturnix coturnix japonica, requirement, serotonin

\section{Introdução}

A formulação de dietas para codornas japonesas baseia-se no conceito de proteína bruta, resultando em dietas com conteúdo aminoacídico em excesso. Qualquer aminoácido que esteja em excesso relativo ao primeiro aminoácido limitante será oxidado e o nitrogênio, excretado.
O triptofano pertence à classe dos aminoácidos essenciais, ou seja, não são produzidos pelo animal ou são produzidos em velocidade muito lenta, não satisfazendo às suas necessidades. Dependendo da dieta, este aminoácido pode ser considerado como terceiro limitante para aves, seguido da metionina e da lisina. Segundo Smith et al. (1983), a via de oxidação do triptofano leva à produção de serotonina no cérebro e, em razão deste fato,

Este artigo foi recebido em 26/1/2007 e aprovado em 17/12/2007. 
alguns trabalhos têm sido realizados visando testar o efeito sedativo do triptofano, via serotonina.

De acordo com o NRC (1994), a exigência de triptofano total para codornas japonesas em fase inicial e de reprodução é de 0,22 e 0,19\%, com 24 e 20\% de PB e 2.900 kcal de EM/kg de ração, respectivamente. Shim \& Lee (1993) reportaram que, para ótima produção de ovos e eficiência alimentar, as dietas de codornas em postura devem conter, em aminoácidos totais, 1,0\% de lisina, 0,43\% de metionina, $0,18 \%$ de triptofano e $0,63 \%$ de treonina. No entanto, trabalhos realizados por Shim \& Vohra (1984) determinaram a exigência de $0,25 \%$ de triptofano total. Leeson \& Summers (1991) discordaram dos autores anteriores, recomendando $0,22 \%$ de triptofano total na dieta de codornas na fase de produção.

Em decorrência da carência de pesquisas sobre a exigência nutricional de triptofano digestível para codornas, objetivou-se com este trabalho avaliar os níveis de triptofano digestível em dietas para codornas japonesas em fase de produção.

\section{Material e Métodos}

Este trabalho foi realizado no Setor de Avicultura do Departamento de Zootecnia, da Universidade Federal de Viçosa, no período de 13 de julho a 13 de setembro de 2005.

Quatrocentas codornas fêmeas (Coturnix coturnix japonica) com 21 semanas de idade foram submetidas a três períodos experimentais de 21 dias cada. O delineamento experimental foi em blocos ao acaso, constituído por oito blocos, para evitar o efeito da produção de ovos sobre os tratamentos. As dietas experimentais foram constituídas de cinco relações triptofano digestível: lisina digestível, com oito repetições de 10 aves por unidade experimental.

As aves foram alojadas em galpão de alvenaria e distribuídas em gaiolas de arame galvanizado (1,0 $\mathrm{m}$ de comprimento $\times 0,25 \mathrm{~m}$ de largura $\times 0,20 \mathrm{~m}$ de altura), dispostas em três andares. Cada gaiola foi subdividida em duas repartições iguais de $0,50 \mathrm{~m}$, nas quais foram alojadas dez aves, fornecendo área de $125 \mathrm{~cm}^{2} /$ ave. Sobre o piso de cimento, abaixo das gaiolas, foi colocada uma camada de maravalha, para absorção da umidade das excretas. O comedouro e o bebedouro foram do tipo calha, em chapa metálica galvanizada, dispostos ao longo das gaiolas.

As dietas e a água foram fornecidas à vontade. $\mathrm{O}$ programa de luz utilizado foi de 17 horas de luz (natural + artificial), com o uso de um controlador de luz do tipo “timer”. As temperaturas de máxima e mínima e a umidade relativa do ar foram registradas diariamente, por meio de termômetros de máxima e mínima e de bulbo seco e bulbo úmido, localizados em um ponto central entre as fileiras de gaiolas.

As dietas foram formuladas com base nas composições dos ingredientes apresentados por Rostagno et al. (2000) e as exigências nutricionais das codornas, de acordo com o NRC (1994), exceto para alguns nutrientes (Tabela 1).

A exigência dos aminoácidos seguiu as recomendações do NRC (1994), porém foram acrescidos em 4\%, objetivando assegurar que não ocorresse nenhuma deficiência dos mesmos, exceto para lisina, metionina + cistina e treonina digestíveis, que seguiram outras recomendações. A exigência em lisina digestível seguiu as recomendações de Pinto et al. (2003a), sendo utilizada em nível sub-ótimo, fixada para manter-se em 1\%. Já a exigência em metionina + cistina foi baseada nas recomendações de Pinto et al. (2003b), acrescidas de 4\%, e a de treonina digestível, na recomendação de Umigi et al. (2007). A exigência de cálcio seguiu a recomendação de Pereira (2004).

As dietas foram formuladas de forma que todas fossem isocalóricas e isoprotéicas, variando em cinco níveis de suplementação de L-triptofano (0,00; 0,04; 0,08; 0,12 e $0,16 \%$ ), perfazendo 0,$120 ; 0,160 ; 0,200 ; 0,240$ e $0,280 \%$ de triptofano digestível, contendo $20 \%$ de PB e $2.900 \mathrm{kcal}$ de $\mathrm{EM} / \mathrm{kg}$, constituindo assim os tratamentos experimentais, correspondendo à relação triptofano: lisina digestível de 12,$0 ; 16,0 ; 20,0 ; 24,0$ e 28,0\%, respectivamente. As diferenças entre os equivalentes protéicos de triptofano e de ácido glutâmico nos diferentes níveis de triptofano em avaliação foram compensadas pelo amido de milho.

Os parâmetros de desempenho analisados foram consumo de ração (g/ave/dia), consumo de triptofano (mg/ave/dia), produção de ovos (\%/ave/dia), peso médio dos ovos (g), massa de ovos (kg/ave/dia) e conversão alimentar (kg de ração/kg de ovos e por dúzia de ovos). A avaliação do consumo de ração foi determinada pela diferença entre a ração fornecida e a sobra de cada período experimental. Nos casos em que houve mortalidades, o consumo médio foi corrigido descontando-se as aves mortas, obtendo-se o consumo médio verdadeiro para a unidade experimental em questão. A coleta dos ovos foi realizada diariamente às $8 \mathrm{~h}$ e a produção foi calculada em porcentagem/ave/dia. Para obtenção do peso médio dos ovos, os mesmos foram coletados, identificados e pesados, nos últimos três dias de cada período experimental, de acordo com a parcela. A massa de ovos foi determinada pelo peso médio dos ovos multiplicado pela produção, expressa em gramas de ovo/ave/dia. A conversão alimentar foi calculada dividindo-se o consumo médio de ração pela produção média de ovos em quilogramas (kg/kg) e dúzias (kg/dz.). 
Tabela 1 - Composição em ingredientes e nutricional da dieta basal (\%MN)

\begin{tabular}{|c|c|}
\hline Ingrediente & $\%$ \\
\hline Milho & 58,437 \\
\hline Farelo de glúten $60 \%$ & 10,000 \\
\hline Farelo de soja & 5,808 \\
\hline Farelo de trigo & 7,000 \\
\hline Farinha peixe $55 \%$ & 3,000 \\
\hline Farinha carne ossos $45 \%$ & 2,900 \\
\hline Óleo soja & 1,725 \\
\hline Fosfato bicálcico & 0,110 \\
\hline Calcário & 6,806 \\
\hline Sal & 0,212 \\
\hline L-Lisina HCl (78\%) & 0,586 \\
\hline DL-metionina (99\%) & 0,248 \\
\hline L-treonina (99\%) & 0,092 \\
\hline L-valina $(99 \%)$ & 0,055 \\
\hline Mistura vitamínica ${ }^{1}$ & 0,100 \\
\hline Mistura mineral $^{2}$ & 0,050 \\
\hline Antioxidante $\mathrm{BHT}^{3}$ & 0,010 \\
\hline Cloreto de colina $60 \%$ & 0,060 \\
\hline Avilamicina $10 \%^{4}$ & 0,055 \\
\hline L-triptofano (99\%) & 0,000 \\
\hline Ácido glutâmico & 2,714 \\
\hline Amido & 0,032 \\
\hline \multicolumn{2}{|c|}{ Composição nutricional calculada } \\
\hline EM (kcal/kg) & 2900 \\
\hline PB (\%) & 20,0 \\
\hline Сa $(\%)$ & 3,200 \\
\hline $\mathrm{P}$ disponível (\%) & 0,400 \\
\hline $\mathrm{Na}(\%)$ & 0,150 \\
\hline Lisina digestível (\%) & 1,000 \\
\hline Met. + Cist. digestível (\%) & 0,840 \\
\hline Treonina digestível (\%) & 0,650 \\
\hline Triptofano digestível (\%) & 0,120 \\
\hline \multicolumn{2}{|c|}{ 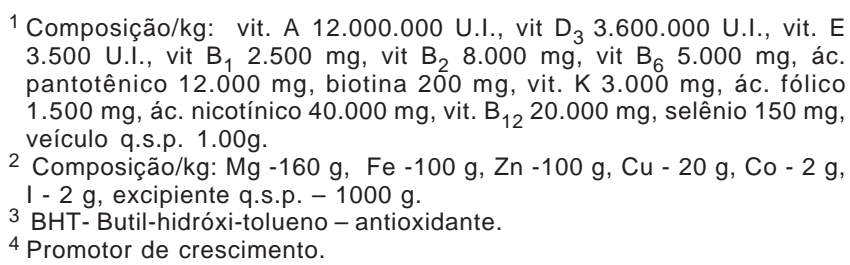 } \\
\hline
\end{tabular}

As análises estatísticas dos resultados obtidos foram feitas utilizando-se o programa SAEG - Sistema para Análises Estatísticas e Genéticas (UFV, 1999). Os efeitos dos níveis de triptofano digestível foram estudados por meio de análises de variância e regressão e os graus de liberdade dos fatores avaliados, desdobrados nos efeitos linear e quadrático, para escolha do modelo de regressão, linear, quadrático ou do modelo descontínuo LRP - Linear Response Plateau (Braga, 1983). Foram considerados o maior valor do coeficiente de determinação $\left(R^{2}\right)$ e a significância a 5 ou $1 \%$ de probabilidade de acordo com o teste $\mathrm{F}$, sendo respeitada a resposta biológica das aves. $\mathrm{Na}$ ausência de interações significativas ( $\mathrm{P}>0,05)$, os níveis de triptofano digestível foram estudados como efeitos principais.

\section{Resultados e Discussão}

Não houve interação $(\mathrm{P}>0,05)$ dos níveis de triptofano digestível $\times$ períodos experimentais, para nenhuma das variáveis estudadas, exceto para o consumo de triptofano (Tabela 2).

Observou-se que as codornas apresentaram maior consumo de ração $(\mathrm{P}<0,01)$ no 3 o período experimental, devido ao avanço na idade das aves, que normalmente aumenta o consumo. No entanto, não houve diferenças significativas $(\mathrm{P}>0,05)$ entre os níveis de triptofano para o consumo de ração. Este resultado está de acordo com os encontrados por Antar et al. (2004) e Deponti et al. (2004), quando trabalharam com galinhas poedeiras.

Os resultados obtidos podem ser justificados pelo fato de as aves não terem sido expostas a situações estressantes, ou seja, situações em que o triptofano poderia

Tabela 2 - Efeito dos níveis de triptofano digestível nas dietas e dos períodos experimentais sobre consumo de ração (CR), consumo de triptofano (CTRP), produção dos ovos (PO) e peso médio dos ovos (PMO) de codornas japonesas

\begin{tabular}{|c|c|c|c|c|c|c|c|c|c|}
\hline \multirow[t]{2}{*}{ Item } & \multicolumn{5}{|c|}{ Nível de triptofano digestível (\%) } & \multicolumn{3}{|c|}{ Período $^{3}$} & \multirow[t]{2}{*}{$\mathrm{CV}(\%)$} \\
\hline & 0,12 & 0,16 & 0,20 & 0,24 & 0,28 & 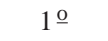 & $2 \underline{0}$ & $3 \underline{0}$ & \\
\hline $\mathrm{CR}^{1}$ (g/ave/dia) & 21,47 & 21,71 & 21,36 & 21,36 & 21,61 & $21,37 b$ & $20,67 c$ & $22,46 \mathrm{a}$ & 5,50 \\
\hline $\mathrm{CTRP}^{2}$ (mg/ave/dia) & 25,76 & 34,74 & 42,73 & 51,27 & 60,50 & $42,76 b$ & $41,19 c$ & $45,04 \mathrm{a}$ & 5,51 \\
\hline $\mathrm{PO}^{2}$ (\%/ave/dia) & 83,58 & 85,32 & 84,92 & 86,53 & 85,81 & $82,50 b$ & $86,23 \mathrm{a}$ & $86,96 \mathrm{a}$ & 3,80 \\
\hline $\mathrm{PMO}^{1}(\mathrm{~g})$ & 10,94 & 10,80 & 10,87 & 10,93 & 10,93 & $10,74 b$ & $10,92 \mathrm{a}$ & $11,02 \mathrm{a}$ & 2,67 \\
\hline
\end{tabular}

\footnotetext{
${ }_{1}^{1}$ Efeito não-significativo $(P>0,05)$.

2 Efeito linear $(P<0,01)$.

3 Médias seguidas de letras diferentes, na mesma linha, diferem a 5\% pelo teste SNK.
} 
ser mais exigido, visto que este aminoácido, por ser precursor da serotonina, promove sensação de bem-estar às aves e, assim, pode aumentar o consumo. Porém, Russell \& Harms (1999), Harms \& Russell (2000), Peganova et al. (2003) e Peganova \& Eder (2003), trabalhando com galinhas poedeiras, encontraram efeito significativo dos níveis de triptofano sobre o consumo de ração, de forma que, elevando-se o nível de triptofano das dietas, aumentou-se o consumo.

Os níveis de triptofano das dietas influenciaram $(\mathrm{P}<0,01)$ o consumo deste aminoácido, que aumentou de forma linear com o incremento dos níveis nas dietas, conforme a equação $\hat{Y}=-0,0012+215,00 X ; R^{2}=1,00$. Também Russell \& Harms (1999), Harms \& Russell (2000), Peganova et al. (2003), Antar et al. (2004) e Deponti et al. (2004) verificaram variação no consumo de triptofano, quando trabalharam com galinhas poedeiras, resultado decorrente do aumento dos níveis de triptofano nas dietas.

Houve efeito $(\mathrm{P}<0,01)$ dos níveis de triptofano nas dietas sobre a produção de ovos das codornas, variando de forma linear, de acordo com a equação $\hat{Y}=81,28+21,16 X$; $\mathrm{R}^{2}=0,66$. Para cada $1 \%$ de triptofano a mais na dieta, a produção de ovos aumentou em 21,16\% até o nível máximo de $0,2142 \%$ de triptofano digestível, estimado pelo modelo de regressão LRP. Houve pouca variação dos dados para produção de ovos, entre os tratamentos, com exceção do menor nível estudado $(0,12 \%)$, que apresentou menor produção, sendo este nível muito abaixo do recomendado pelo NRC (1994). Os resultados confirmaram aqueles encontrados por Russell \& Harms (1999), Harms \& Russell (2000) e Deponti et al. (2004), que trabalharam com galinhas poedeiras e verificaram melhoria na produção, à medida que níveis crescentes de triptofano foram adicionados às dietas. Esses autores constataram que a produção foi significativamente menor com poedeiras alimentadas com dietas que continham níveis abaixo de $0,15 \%$ de triptofano. No entanto, estes resultados divergem daqueles encontrados por Peganova \& Eder (2003) e Antar et al. (2004), que não encontraram efeito significativo dos níveis de triptofano sobre a produção de ovos de galinhas poedeiras. Vários autores (Allen \& Young, 1980; Shim \& Vohra, 1984; Leeson \& Summers, 1991; Shim \& Lee, 1993), trabalhando com codornas japonesas em fase de produção, verificaram exigências de 0,17; 0,25; 0,22 e 0,18\% de triptofano total, respectivamente, para obtenção de máxima produção de ovos.

Verificou-se melhora significativa nos dois últimos períodos experimentais sobre a produção de ovos. A menor produção de ovos obtida no 1 oㅡ período pode ser esclarecida, quando se observa a temperatura média registrada neste período, que foi relativamente baixa, média de $18^{\circ} \mathrm{C}$. Foram obtidas no $2^{\underline{0}}$ e $3^{\circ}$ períodos as médias de 21 e $22^{\circ} \mathrm{C}$, respectivamente, sugerindo que no $1^{\mathrm{o}}$ período pode ter havido alteração no metabolismo das aves, que passaram a gastar mais energia para o aquecimento corporal, energia que poderia ser utilizada para produção.

Observou-se efeito não-significativo $(\mathrm{P}>0,05)$ para o peso médio dos ovos de acordo com os níveis de triptofano digestível das dietas. Da mesma forma, Russell \& Harms (1999), Peganova \& Eder (2003) e Deponti et al. (2004), avaliando níveis de triptofano total em dietas de galinhas poedeiras, também não encontraram efeito sobre esta variável. Porém, os resultados apresentados por Harms \& Russell (2000) e Antar et al. (2004) estão em desacordo com os obtidos nesta pesquisa, tendo sido verificado efeito dos tratamentos sobre o peso de ovos de galinhas poedeiras. Nesses trabalhos foram utilizadas dietas com diferentes concentrações de proteína e outros aminoácidos, fato que pode explicar o resultado verificado, visto que a variável peso de ovos é influenciada pelo consumo diário de proteína pela poedeira. De acordo com Pinto et al. (2002), o nível protéico da ração influencia positivamente o peso dos ovos, pelo fato de as poedeiras terem pouca habilidade em estocar eficientemente a proteína, dependendo de suficiente ingestão diária deste nutriente, a fim de suprir as exigências para produção de ovos mais pesados. Logo, pode-se inferir a partir dos resultados obtidos neste trabalho para peso médio dos ovos que o aminoácido triptofano possui pouca influência sobre esta variável.

Verificou-se que as codornas produziram ovos mais pesados no $2^{\underline{0}}$ e $3^{\underline{0}}$ períodos. O peso médio dos ovos no $3^{0}$ período foi $2,5 \%$ maior que o encontrado no $1 \stackrel{0}{ }$, estando em conformidade com o fato de que as codornas, assim como as poedeiras, normalmente, aumentam o tamanho dos ovos com o avanço da idade e, conseqüentemente, seu peso.

Os níveis de triptofano digestível não influenciaram $(\mathrm{P}>0,05)$ os resultados de massa de ovos (Tabela 3$)$. As codornas apresentaram maiores valores para massa de ovos no $2^{\underline{0}}$ e $3^{\underline{0}}$ períodos, efeito que pode ser esclarecido quando se observa aumento na produção e no peso dos ovos nos referidos períodos e, conseqüentemente, espera-se que a massa de ovos também aumente, visto que estas variáveis estão positivamente correlacionadas.

Embora não tenham sido observadas diferenças significativas neste trabalho para a massa de ovos das aves alimentadas com diferentes níveis de triptofano, verificou-se que, em geral, as dietas com maiores níveis de 
Tabela 3 - Efeito dos níveis de triptofano digestível nas dietas e dos períodos experimentais sobre a massa de ovos (MO), conversão alimentar por massa de ovo (CAMO) e conversão alimentar por dúzia de ovos (CADZ) de codornas japonesas

\begin{tabular}{|c|c|c|c|c|c|c|c|c|c|}
\hline \multirow[t]{2}{*}{ Item } & \multicolumn{5}{|c|}{ Nível de triptofano digestível (\%) } & \multicolumn{3}{|c|}{ Período $^{2}$} & \multirow[t]{2}{*}{$\mathrm{CV}(\%)$} \\
\hline & 0,12 & 0,16 & 0,20 & 0,24 & 0,28 & $1 \underline{0}$ & $2 \underline{0}$ & $3 \underline{0}$ & \\
\hline $\mathrm{MO}^{1}$ (g/ave/dia) & 9,14 & 9,22 & 9,23 & 9,46 & 9,38 & $8,87 b$ & $9,42 \mathrm{a}$ & $9,58 a$ & 9,56 \\
\hline $\mathrm{CAMO}^{1}(\mathrm{~kg} / \mathrm{kg})$ & 2,37 & 2,38 & 2,33 & 2,27 & 2,32 & $2,43 a$ & $2,21 b$ & $2,36 a$ & 7,97 \\
\hline $\mathrm{CADZ}^{1}(\mathrm{~kg} / \mathrm{dz})$. & 0,311 & 0,307 & 0,304 & 0,298 & 0,304 & $0,313 a$ & $0,289 b$ & $0,312 \mathrm{a}$ & 8,19 \\
\hline
\end{tabular}

${ }^{1}$ Efeito não-significativo $(P>0,05)$.

${ }^{2}$ Médias seguidas de letras diferentes, na mesma linha, diferem em $5 \%$ pelo teste SNK.

triptofano digestível (0,24 e 0,28\%) proporcionaram maior massa de ovos em valores numéricos, resultando em 3,38 e $2,56 \%$ a mais, respectivamente, que o obtido com a dieta que possuía o menor nível de triptofano (0,12\%). Peganova \& Eder (2003) e Antar et al. (2004) também não encontraram efeito significativo dos níveis de triptofano para massa de ovos, quando trabalharam com galinhas poedeiras.

Entretanto, Russell \& Harms (1999) e Deponti et al. (2004), também trabalhando com galinhas poedeiras, observaram que o aumento dos níveis de triptofano nas dietas elevou a massa de ovos.

Os níveis de triptofano digestível não influenciaram ( $P>0,05)$ a conversão alimentar por massa e dúzia de ovos das codornas. Os resultados encontrados neste trabalho para conversão alimentar por massa de ovos corroboram aqueles apresentados por Peganova \& Eder (2003) e Deponti et al. (2004), trabalhando com diferentes níveis de triptofano total nas dietas de galinhas poedeiras.

Observaram-se melhores resultados para conversão alimentar por massa e dúzia de ovos no $2^{2}$ período, em decorrência do menor consumo de ração, da melhor produção e massa de ovos obtidos no referido período.

\section{Conclusões}

A exigência em triptofano digestível para codornas japonesas de 21 a 30 semanas de idade, com base na produção de ovos, estimada pelo modelo de regressão LRPLinear Response Plateu, foi de 0,21\% da dieta, correspondendo ao consumo diário de 45,0 mg/ave de triptofano digestível, seguindo a relação triptofano digestível: lisina digestível de $21 \%$.

\section{Literatura Citada}

ALLEN, N.K.; YOUNG, R.J. Studies on the amino acid protein requirements of laying Japanese quail (Coturnix coturnix japonica). Poultry Science, v.59, n.9, p.2029-2037, 1980.

ANTAR, R.S.; HARMS, R.H.; SHIVAZAD, M. et al. Performance of commercial laying hens when six percent corn oil is added to the diet at various ages and with different levels of tryptophan and protein. Poultry Science, v. 83, n.3, p.447455, 2004.

BRAGA, J.M. Avaliação da fertilidade do solo (Ensaios de campo). Viçosa, MG: Imprensa Universitária, 1983. 101p. (Cadernos, 156).

DEPONTI, B.J.; FARIA, D.E.; SILVA, F.H.A. et al. Determinação da exigência de triptofano para poedeiras brancas com 51 semanas de idade. Revista Brasileira de Ciência Avícola, v.6, p.31, 2004.

HARMS, R.H.; RUSSELL, G.B. Evaluation of tryptophan requirement of the commercial layer by using a corn-soybean meal basal diet. Poultry Science, v.79, n.5, p.740-742, 2000.

LEESON, S.; SUMMERS, J.D. Commercial poultry nutrition. Guelph: University Books, 1991. 283p.

NATIONAL RESEARCH COUNCIL - NRC. Nutrient requirements of poultry. Washington, D.C.: National Academy Press, 1994. $155 p$.

PEGANOVA, S.; EDER, K. Interactions of various supplies of isoleucine, valine, leucine e tryptophan on the performance of laying hens. Poultry Science, v.82, n.1, p.100-105, 2003.

PEGANOVA, S.; HIRCHE, F.; EDER, K. Requirement of tryptophan in relation to the supply of large neutral amino acids in laying hens. Poultry Science, v.82, n.5, p.815-822, 2003.

PEREIRA, C.A. Exigência nutricional de cálcio para codornas japonesas durante o pico de postura. Viçosa, MG: Universidade Federal de Viçosa, 2004. 60p. Dissertação (Mestrado em Zootecnia) - Universidade Federal de Viçosa, 2004

PINTO, R.; FERREIRA, A.S.; ALBINO, L.F.T. et al. Níveis de proteína e energia para codornas japonesas em postura. Revista Brasileira Zootecnia, v.31, n.4, p.1761-1770, 2002.

PINTO, R.; FERREIRA, A.S.; DONZELE, J.L. et al. Exigência de lisina para codornas japonesas em postura. Revista Brasileira Zootecnia, v.32, n.5, p.1182-1189, 2003a.

PINTO, R.; DONZELE, J.L.; FERREIRA, A.S. et al. Exigência de metionina mais cistina para codornas japonesas em postura. Revista Brasileira Zootecnia, v.32, n.5, p.1166-1173, 2003b.

ROSTAGNO, H.S.; ALBINO, L.F.T.; DONZELE, J.L. et al. Tabelas brasileiras para aves e suínos - composição de alimentos e exigências nutricionais. Viçosa, MG: Editora UFV, 2000. 141p.

RUSSELL, G.B.; HARMS, R.H. Tryptophan requirement of the commercial hen. Poultry Science, v.78, n.9, p.1283-1285, 1999.

SHIM, K.F.; LEE, T.K. Effect of dietary essencial amino acid on egg production of laying Japanese quail. Singapore Journal of Primary Industry. v.21, n.2, p.72-75, 1993.

SHIM, K.F.; VOHRA, P. A review of the nutrition of japanese quail. Journal World's Poultry Science, v.40, n.3, p.261-274, 1984.

SMITH, E.L.; HILL, R.L.; LEHMAN, I.R. et al. Principles of biochemistry. 7.ed. New York: McGraw-Hill Book, 1983. p.639-641.

UMIGI, R.T.; BARRETO, S.L.T.; DONZELE, J.L. et al. Níveis de treonina digestível em dietas para codornas japonesa em postura. Revista Brasileira de Zootecnia, v.36, n.6, p.1868-1874, 2007.

UNIVERSIDADE FEDERAL DE VIÇOSA - UFV. Sistema para Análises Estatísticas e Genéticas - SAEG. Viçosa, MG: Fundação Arthur Bernardes, 1999. (CD-ROM). 